\title{
Analysing the relationships between students and mathematics: A tale of two paradigms.
}

In this article we argue the need to use inter-disciplinary paradigms to make sense of a range of findings from a research project. We developed a methodology using iPad diaries to uncover young students' thinking - mathematical, social and affective - so as to better understand their experiences of mathematics. These students, predominantly from Year 3 and Year 6 were drawn from economically and socially distinct schools in Queensland and New South Wales, Australia. This article builds on previous research, where we outlined the unique methodology that we developed over three iterations to collect student attitudinal comments regarding mathematics. The comments we collected gave significant insights into the experiences of, and possibilities for, the mathematics education of young learners (Authors 2015). Here we use these findings to explore the value of two paradigms to explain student experiences towards mathematics among primary school students from different social backgrounds. In so doing, we develop an explanatory model for the socially-differentiated outcomes in students' responses and then use this explanatory model to analyse student responses from the two most socially disparate schools in our research.

This article explores comments about mathematics from different cohorts of students attending primary schools in Queensland or New South Wales. For this article we draw on the data from the two disparate schools, from our broader research project, in terms of social background. Each cohort was comprised of Year 2/3 (or equivalent) and Year 6 students. These students are approximately $8 / 9$ years and $11 / 12$ years of age respectively. These year levels were selected as they provide information regarding mathematics at two key junctures of schooling; namely the end of the early years' phase (Year 2/3) and the end of the primary school phase of learning (Year 6). This article builds on three iterations of previous research, where we outlined the unique methodology we developed to collect student attitudinal comments regarding mathematics. These comments gave significant insight into the experiences and possibilities for mathematics education of young learners (Authors 2015). In previous research we have used iPad data to provide an insight into the decline in positive attitudes towards mathematics occurring early in Primary School (Authors 2015) which likely contributes to a decline in enrolment in mathematics classes once they become non-compulsory.

For this article, we digress from the usual writing norms where authors locate the research in a review of particular literatures on topics contained within the framing of the article. It is not the intent of this article to position the research within a particular corpus of literature. Rather, what we have observed in this study is the need for us to develop a novel way of reconceptualising the data. As such, we use the construct of a paradigm which can be seen as a collection of theories that come to represent a particular way of seeing the world. We draw on two paradigms. First a psychological one which has significant currency in the field of mathematics education as evident in organisations such as "The International Group for the Psychology of Mathematics Education" often referred to as PME and high stakes journals such a Learning and Instruction, Cognition and more specifically related to mathematics education, the Journal for Research in Mathematics 
Education where there is very powerful influence and recognition of psychological discourses, practices and methods in mathematics education. While there are other journals such as For the Learning of Mathematics that is more multidisciplinary, there is not a high stakes journal for the Sociology of Mathematics Education. Theories are used within the two paradigms that offer particular ways to describe and analyse phenomenon and are remarkably different between the two paradigms. In part, this is due to the unit of analysis in the two paradigms, but also shaped by the assumptions that underpin and permeate the paradigms, as well as methods and forms of analysis that are seen to be legitimate within the paradigm. As such, in this article, we seek to use data from our data set to propose different ways of describing and analysing the data. For the purposes of this article, the data are used to be illustrative examples of the ways in which they can be interpreted using the constructs and theories within the two paradigms.

In this current research, we explore the value of two different paradigms to explain the attitudes towards mathematics among primary school students from different social backgrounds as considering the data through the lens of two different paradigms gives a richer understanding of the data. In so doing we develop an explanatory model for the socially differentiated outcomes in students' responses. We then use this explanatory model to analyse students' responses from the two most disparate schools. We have intentionally sought to unite the two paradigms to explain outcomes in a larger project. The key conceptual premise underpinning this article is that any single theory is inadequate in explaining students' differentiated discussions about their experiences of, and attitudes towards, mathematics in primary classrooms. A more comprehensive account can be created by drawing on different paradigms to understand socially diverse settings and how these create opportunities for understanding the individual within a social context.

What emerged from the data were distinct patterns in responses that largely aligned with the socio-economic backgrounds of the students. To this end, focusing on an individual was limiting, since it failed to recognise the structuring practices of mathematics classrooms and the habitus (simply put - the embodiment of culture) with which students entered these classrooms, as well as the mathematical habitus which could be built as a consequence of their immersion into the practices they described. Similarly, focusing solely on the social backgrounds of the students limited the richness in the responses offered by the students in terms of how they were actively constructing themselves as learners. It is through the twin lenses of the individual, and the social construct in which they experience mathematics, that the student attitudinal data is examined. These lenses revealed a number of common themes in relation to the responses across the two schools.

\section{Literature Review}

Due to our intention to focus on the two paradigms in accounting for student interaction with mathematics, we present here only a snapshot of the literature on student attitudes towards mathematics (see Authors 2015 for a full account). Much of the extant literature suggests that secondary school students, where they have the choice, are "opting out" of mathematics (for example, Brown 2009). While there are differences internationally, the trend in Australia is for students to opt out of complex mathematics options when this is possible - usually in the senior years of schooling (Lamb 2012). The access to high stakes subjects, such as the more complex levels of mathematics is also differentiated along socio-economic lines (Tranter 2012) which provides a rationale for the need to better understand the processes whereby students decide to opt out of mathematics, or are 
'squeezed' out. While the physical withdrawal option is not available to primary school students (given that mathematics is compulsory) they may instead be psychologically distancing themselves from engagement with mathematics (which likely pre-empts the later physical withdrawal from mathematics in secondary years). The literature suggests that this "opting out" is based upon negative experiences of, and attitudes towards, mathematics and that these attitudes and experiences are often associated with shame, inadequacy, anxiety and hopelessness, resulting in declined performance (Lewis 2014).

Overwhelmingly, existing research into beliefs, attitudes and emotions come together to shape the self-concept of the learner. Collectively this extensive research has indicated an important and inseparable relationship between cognitive and affective mathematical domains. It is neither our intent nor purpose to review this literature, but rather to take this collective research base to inform and locate the individualism of the approaches within the psychological paradigm. The affective domain of learning is a key feature of the data upon which we later draw to highlight the individualism of the psychological paradigm. For example, Radford (2015) argued that emotions are an integral part of thinking. Similarly, Ma and Kishor (1997) suggest "a cognitive component to every affective objective and an affective component to every cognitive objective" (p. 26). The clear conclusion from the existing research from the psychological paradigm is that any analysis of engagement with mathematics must encompass both cognitive and affective domains. For example, some researchers have linked the notion of (gendered) self-concept in mathematics to opting out and burnout in mathematics (Korhonene, Tapola, Lannanmaki and Anio 2016). What is less well known in the literature is when this withdrawal process from mathematics commences, whereby "the 'curiosity machine' [the student] turns into a "mathematical idiot" (Di Martino and Zan 2010, p. 28) and how this aversion to mathematics may be avoided or at the very least minimised.

\section{Conceptual Framing}

It is also beyond the scope of this article to provide a detailed account of the various theories underpinning the major paradigms in mathematics, as this restricts the space available to discuss our selected excerpts in terms of theory building. What is provided is a brief discussion of the major shifts and foci within the various fields to illuminate key moves in contemporary thinking regarding the impact of individual construction of mathematical identities in terms of access (and marginalisation) in school mathematics.

Table One: Key Paradigms in Mathematics Education

\begin{tabular}{|c|c|c|c|}
\hline & Psychological & Sociological & Post-Modernist \\
\hline Key terms & $\begin{array}{l}\text { Confidence, beliefs } \\
\text { dispositions, }\end{array}$ & $\begin{array}{l}\text { Social groups } \\
\text { Differences, equity }\end{array}$ & $\begin{array}{l}\text { Identity formation } \\
\text { Intersubjectivity }\end{array}$ \\
\hline $\begin{array}{l}\text { Explanatory } \\
\text { concept }\end{array}$ & $\begin{array}{l}\text { Individualistic } \\
\text { Self concept }\end{array}$ & Habitus & Identity \\
\hline Theorists & Bandura, Hannulu & Bourdieu, Jorgensen & Foucault, Walshaw \\
\hline
\end{tabular}

While there are many theories upon which researchers can draw to explain phenomenon, we have drawn on two paradigms: psychology in which the focus is on the individual and 
how an individual sees, interprets and acts in a social world; and sociology in which the focus is more on the social and structures that shape individuals. Within each of these paradigms there is a vast array of theories that are used to explain these phenomenon. It is our intent in this article to try to unite these paradigms so as to have a richer explanation of the data that can be collected in a research article. For this reason, we consider the data used herein to be more illustrative in terms of the paradigms. It was valuable for this article that the data that we use comes from two socially different schools, and as such, we can draw on these data as they are likely to represent the different views of the social strata as much as the individual who expressed them.

We can see the vastly different perspectives of psychology and sociology in the following quotes from leading proponents of these two perspectives. Allport (nd) describes the sense of self as coming through an individualistic perspective where a person seeks to understand himself/herself in relation to others.

The outlines of the needed psychology of becoming can be discovered by looking within ourselves; for it is knowledge of our own uniqueness that supplies the first, and probably the best, hints for acquiring orderly knowledge of others (Gordon W. Allport nd).

In contrast, Marx takes a wide social perspective in which the social relations shape the person.

Society does not consist of individuals but expresses the sum of interrelations, the relations within which these individuals stand (Marx, nd).

Aristotle (nd) is often cited as saying "Give me a child until he is 7 and I will show you the man" suggesting that the early years of life shape the person we become. For some this can be interpreted through a psychological framework, whereas for others it can be interpreted through a sociological framing. It is our intent in this article to explore the potential richness of drawing on both perspectives offered through the paradigms to explain the students' responses in our data.

In terms of the psychological paradigm, we argue that the focus is largely on the individual student and their personalisation of learning - in line with Allport cited above. Student dispositions in particular are dominant within this paradigm. An insight provided by Lewis (2013) suggests that "motivation and emotion may be more central to an understanding of the phenomenon of disaffection than that of a quantitative study of attitude" (p.70). Similarly Brown, Brown and Biddy, (2012) argue that there were psychological internalisations for students selecting to opt out of further study in mathematics.

In contrast to the embodiment and internalisation of dispositions towards mathematics as an individual phenomenon, others have suggested that the sociological practices of school mathematics may create opportunities to overtly and/or covertly marginalise particular groups of students (See Author 1 et al. 2014). The (critical) sociological paradigm emphasises systems and structures, including practices, and how these impact and shape the learning outcomes for students. In exploring the social practices of the schools, we draw on Bourdieu (1997) who explains that educators need to understand the processes and practices around the conversion of social and cultural backgrounds into school success. The responses offered by the students in this research were highly varied, and have consequences both for their current relationship with school mathematics, and also for future academic success in secondary school mathematics and beyond. This view is argued 
thus:

To fully understand how students from different social backgrounds relate to the world of culture, and more precisely, to the institution of schooling, we need to recapture the logic through which the conversion of social heritage into scholastic heritage operates in different class situations (Bourdieu, Passeron and De Saint Martin 1994, p. 53).

The notion of social heritage thus becomes a central variable in coming to understand differential success in school mathematics. In terms of this project, and for school mathematics in general, we suggest that it is salient to consider the social backgrounds of learners and how this is implicated in the differential outcomes for learners. Using a Bourdieuian framework, the lack of success for some social groups becomes a non-random event, as success or otherwise is partially a product of institutionalised practices of which participants may be totally ignorant. Students (and teachers) accept the success and failures in mathematics as being something related to an innate trait - such as ability, affect, emotion or beliefs; but within a critical sociological framing, the emphasis is more on how practices within mathematics create circumstances for these attributes to be shaped. So, for students who come from socially, culturally or linguistically diverse backgrounds, their potential for success (or not) is more about the practices within schools rather than individual traits. Thus, what becomes important for both psychological and sociological theories is the ways in which learners internalise practices within school mathematics in relation to their positioning within those practices. For some students, the social and cultural habitus with which they enter mathematics classrooms aligns strongly with the practices and discourses within those classrooms. For these students, it is highly likely that they will see themselves as 'good' learners of mathematics. In contrast the reverse is the case for students whose habitus does not align with the practices and discourses valued within the field.

By way of summary (See Table Two) we present the key constructs that we will use to explain the quantitative and qualitative data we collected via the iPads and also present terminology relevant to each construct for each paradigm. These constructs are explored further when we analyse the two profiles we create for each of the schools.

Table Two: Analytic Framework

\begin{tabular}{|c|c|c|}
\hline Construct & Psychological & Sociological \\
\hline Teacher quality & Teacher qualities & Structuring practices \\
\hline $\begin{array}{l}\text { Pedagogy-group } \\
\text { work/individual work }\end{array}$ & Communities of practice & Doxa \\
\hline Ability - who succeeds & Mindsets identity, ability & Habitus and cultural capital \\
\hline $\begin{array}{l}\text { Feelings towards } \\
\text { mathematics }\end{array}$ & Affect, identity & Habitus \\
\hline $\begin{array}{l}\text { Mathematics as a discipline, } \\
\text { purpose }\end{array}$ & Community of practice & Field \\
\hline
\end{tabular}

The terms used in Table Two are drawn from various theoretical perspectives within each paradigm. The constructs are drawn from the student data. The constructs are derived from the comments made by students as coded through our coding process and through the use of Leximancer. For example, if a student were commenting on who was succeeding or not 
in mathematics and discussed this in terms of the student being "smart" or "brainy", as if success were due to some innate characteristic of a student, then the data were coded as being about 'ability'.

\section{Method/Approach}

\section{Collecting Authentic Data on Student Attitudes}

As was the case in the broader research project of which this is a part (Authors 2014; 2015), we again used iPads as the primary data collection tool. Although a recent methodological tool, the collection of data in this manner shares many of the limitations and affordances of more well established digital and analogue methods of collecting information from students regarding mathematics education. Proponents of using video research (Buchwald, Schantz-Laursen and Delmar 2009; Lundström 2013; Noyes 2004b) argue that using videos enables researchers to collect data of a more profound, compelling quality than the data normally collected in interviews, surveys or observations. The suggestion from researchers such as these is that a deepened understanding of the experiences of the students over a period of time can occur via the use of video or audio recording as they provide an opportunity for a researcher to be privy to "otherwise inaccessible aspects of the students experience" (Noyes, 2004b p. 207). Furthermore, the limited literature available suggests that: the use of videos encourages students' voices and the telling of personal narratives (Buchwald, et al., 2009); student voice is critical as it can often be problematic for adult researchers to understand the worldview of students and; video diaries can be a means of empowering participants to speak authentically of the experience under investigation and to thereby "create representations of their own experiences" (Noyes 2004a, p. 7).

Reflecting upon the findings in the literature regarding appropriate paradigms for investigating student attitudes and emotions towards their experience of mathematics education, the following research question emerged: How can the use of psychological and sociological paradigms help to understand student experiences in mathematics and inform future directions for mathematics education?

\section{Data Collection}

Data from three primary schools, each representing different social strata, were collected in the broader project; however, in this article, we report only on data from the two most disparate schools in terms of socio-economic status (ICSEA). The schools were included by purposive selection so that an exploration of social differences could be undertaken. Due to the sample size, statistical significance cannot be established; however, the sample is large enough to allow the continued evaluation of the iPads as a methodology for accessing students' perceptions of school mathematics, and also for the development of theory. A synopsis of the two schools is provided in Table Three. School B is a New South Wales state school (2014 ICSEA: 970) and involved 96 students. School C is a private girls school (2014 ICSEA: 1135) and involved 67 students. With the ICSEA score representing 1,000 as the national mean for a measure of social dis/advantage, each 100 points represents one standard deviation from the mean. As indicated, we investigated students talking about their experiences at two junctures; Year 2/3 - end of the early years and Year 6 - end of Primary school. We focus on the contributions from the students that went beyond short sentence responses to develop deeper insights into students' thinking about 
themselves and their relationship to mathematics.

Table Three: Demographics of the schools - MySchool Website 2015

\begin{tabular}{llll}
\hline & School B & School C & \\
\hline Type of school & State school & $\begin{array}{l}\text { Independent } \\
\text { school }\end{array}$ & girls \\
Year levels & P-6 & P-12 & \\
$\begin{array}{l}\text { ICSEA score } \\
\text { (2013) }\end{array}$ & 970 & 1135 & \\
Enrolments & 268 & & \\
Location & NSW & QLD & \\
\hline
\end{tabular}

As the project developed, we fine-tuned the data collection methodology of using iPads as a means of recording students' experiences of mathematics. Ethical clearance was obtained and student /parent consent was gained prior to their involvement.

\section{Findings and Results}

In School B students used the video functionality of the iPads to record a video. A shared iPad was placed in a tent positioned in an office between pairs of classrooms where students could record their video. In School B, a research assistant downloaded the videos on a regular basis i.e. every second or third school day. In School $\mathrm{C}$ we used a generic email account on each of the iPads such that the students could record their diary entry, using AudioNote app, then email the recording to a secure researcher email address, and then delete their diary (email and internet access were not permitted in School B so this method could not be used). In both School B and School C written prompts (e.g. what would I tell my mum and dad about what I did in maths today?) were placed within a small tent which we used to create a "mathematical thinking space" Across the two schools, 145 separate diary entries were recorded (See Table Four) and this suggests that the students were very comfortable with this approach. In addition to a raw count of the number of entries, examination of the thoughtful nature of many responses (some were as long as five minute recordings) also indicates the usefulness of the methodology for eliciting quality responses from young students. Responses were typically of the following length -

I don' $t$ like when you were listening but you don' $t$ understand the thing that the teacher is asking you to do and you feel a bit scared to ask questions because you might get in trouble or you might be embarrassed. I don't feel sad when I do maths. The teacher could probably help by doing, by explain things a bit more and not getting so hard on kids when they get the questions wrong. I don't like working in groups because it's like if you get a question wrong the whole group will go, oh, you don' $t$ know that question. I don' $t$ really feel happy when I do maths and I don't really feel sad. (School B Year 6)

Overall, we take this as evidence for the success of the iPad as a means of accessing students' thoughts about mathematics and thus will not further discuss the use of iPads. In 
addition to collecting data via the iPads, in order to gain a sense of the type of mathematics environments that existed in each school, the lead researcher regularly visited the classrooms in both School B and School C and observed mathematics lessons being taught. In addition, at the commencement of the data gathering at each site, one or both of the authors completed an archaeological examination of the classrooms (See Zevenbergen and Flavel 2007) - identifying what resources were available, what mathematics artefacts were visible in the rooms etc. This being noted, the main dataset for the chapter are the student recordings.

Table Four: Total number of video / audio entries by school and year level

\begin{tabular}{cccc}
\hline School / Year Level & Year 2/3 & Year 6 & Total \\
\hline B & 65 & 40 & 105 \\
C & 20 & 20 & 40 \\
Combined & 85 & 60 & 145 \\
\hline
\end{tabular}

Although due care was taken at School B, students (and possibly their teachers) could watch the video recordings of others in the time between when they were recorded and when they were cleared from the iPad by the research assistant. Therefore, in order to maximise the privacy of the student recordings, in school $\mathrm{C}$ we used AudioNote - an app for recording sound and drawings - these were sent to the researcher immediately after they were recorded and then the individual students deleted the recordings from the iPad. The use of generic email accounts - e.g. Class 1, Class 2 etc. meant that no individual students could be identified by the researcher, unless they chose to reveal their name. In future research, we will encourage schools to use the AudioNote App and email, rather than video stored on the device, as this method more fully guarantees both the anonymity and security of the diary entries.

The video or audio data were transcribed and then analysed using Leximancer, a software package that undertakes thematic analysis of the frequency of words as well as establishing relationships between terms used by participants. Leximancer allows researchers to visually see the trends and themes (See Diagram 1) that appear in the data set/s (Angus, Rintal and Wiles 2013) 
Diagram 1: Schematic representation of key words from School B

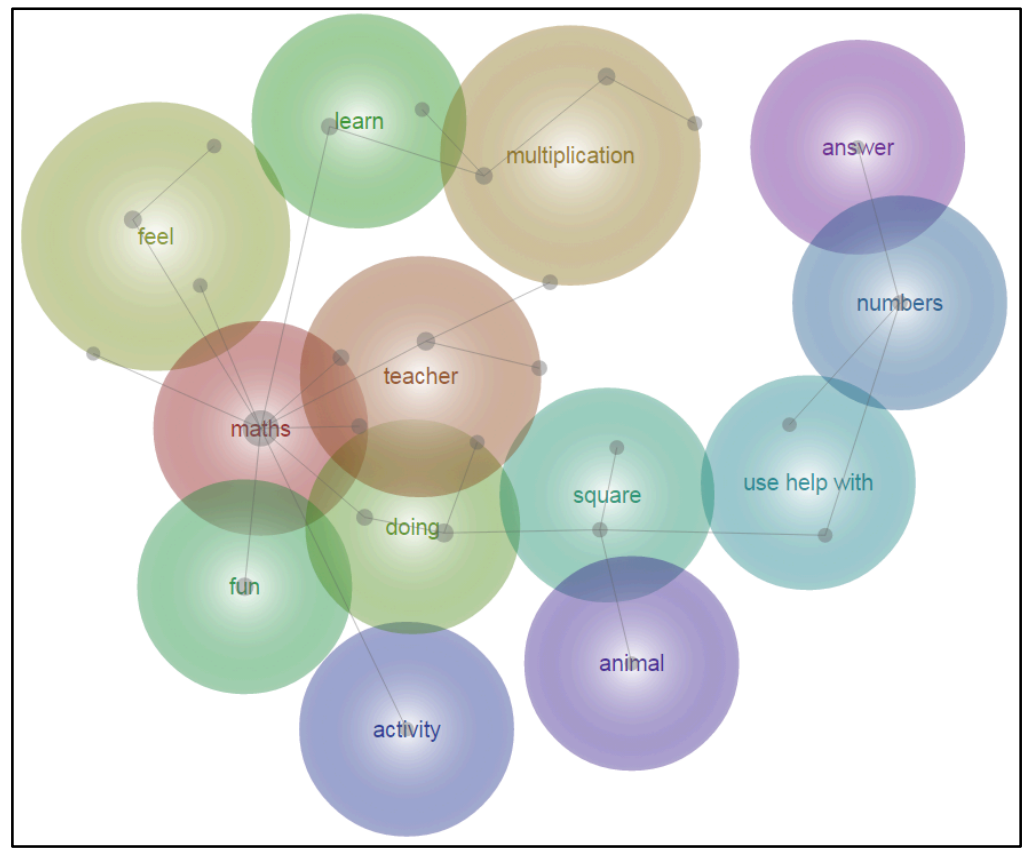

In relation to the data presented in Table Five (below), the number in the Count column is a raw score of the number of times a word was used. The data in the relevance (Rel) column is a score calculated by dividing the frequency of a selected word by the frequency of the most often used word expressed as a percentage. As demonstrated below, some words are used more frequently, and thus are more relevant, in particular schools. For example, the word fun is respectively at School B and C 20\% and 29\%. Some words used do not appear in Table 5, as they did not reach the 5\% relevancy threshold at individual schools; however, their frequency still contributes to the overall relevance in the Leximancer analysis. Other words have been excluded from analysis e.g. words such as "doing", "stuff", "things" as they do not contribute to any understanding of student attitudes towards mathematics; and words such as "food", "animals", "favourite" were excluded as they formed part of the prompt questions which many students read prior to answering.

Table Five: Frequency tables categorised by school (Adapted from Authors 2015)

\begin{tabular}{cccccc}
\hline \multicolumn{2}{c}{ School B } & \multicolumn{3}{c}{ School C } \\
\hline Word & Count & Rel & Word & Count & Rel \\
maths & 262 & $100 \%$ & maths & 175 & $100 \%$ \\
fun & 53 & $20 \%$ & fun & 51 & $29 \%$ \\
feel & 51 & $19 \%$ & teacher & 40 & $23 \%$ \\
teacher & 39 & $15 \%$ & groups & 36 & $21 \%$ \\
times & 33 & $11 \%$ & feel & 26 & $15 \%$ \\
numbers & 27 & $10 \%$ & fractions & 24 & $14 \%$
\end{tabular}




\begin{tabular}{cccccc} 
groups & 25 & $10 \%$ & easy & 19 & $11 \%$ \\
difficult & 22 & $8 \%$ & love & 18 & $10 \%$ \\
easy & 22 & $8 \%$ & probability & 15 & $9 \%$ \\
division & 18 & $7 \%$ & diagrams & 12 & $6 \%$ \\
pods & 12 & $5 \%$ & chunking & 11 & $6 \%$ \\
& & & difficult & 11 & $6 \%$ \\
\hline
\end{tabular}

A second important observation is that, although Leximancer makes connections between words, it does not necessarily take into account all information regarding the specific context of the comments; e.g. "I have fun doing fractions" and "I don't have fun doing fractions" contribute two counts for both fun and fractions and yet have opposite attitudinal content. Hence, further analysis and interpretation was conducted by the researchers in determining the quality and relevance of individual words used by the students. Thus, we have used the frequency count to support a grounded theory approach (Strauss and Corbin 1997) to point us in the direction of further inquiry and the generation of the themes for later discussion. In this way, we could provide insights into the mathematical lifeworlds (Boylan 2010) of students by locating the statements containing the frequently used words, identify the context in which they were used, and then use these insights to generate themes for further analysis.

\section{Explaining Outcomes Through the Two Paradigms}

In the following sections we analyse the visual representations and frequency of words presented in Tables Four and Five and Diagram One using the two major paradigms psychological and sociological - to make sense of the data that were collected. This analysis informed (and confirmed) the substantially different types of comments made by students in the two schools. This process enhances the legitimacy of our claims regarding the differences between the students at each school, discussed in subsequent sections of this article. Before doing so we provide an aggregated profile that is a representation of the dominant trends in the students' responses from the two schools. This gives a sense of the overall habitus of the Year 2/3 and 6 learners at the two schools.

\section{Creating "Aggregated Profiles"}

To provide a snapshot of the profiles of the learners within the schools, we have constructed what we name "aggregated profiles" (see Table Six). The profile for the student cohort at each school is constructed from our earlier analysis of the data (using Leximancer) as to the frequency of responses from students at each research school. Both schools have low levels of student diversity in terms of cultural backgrounds from countries outside Australia, and most students speak English as their first language. We draw on two common themes described by the students: firstly, the ways that they feel towards mathematics; and secondly, their experiences in the mathematics classrooms. We acknowledge that this is a case-study methodology and that our participants are drawn from two schools and there is no attempt to generalise these findings to other schools. Similarly, the study was conducted at a particular point in time, so the data reflect that 
moment in time. So, it is reasonable to acknowledge that the practices described by the students are those that they experienced at that point in time e.g. particular mathematics content or student groupings. What can be observed from the aggregated profiles is that the students reported markedly different experiences and attitudes towards mathematics.

Table Six: Aggregated profiles

\begin{tabular}{|c|c|c|}
\hline & School B & School C \\
\hline \multirow{5}{*}{$\begin{array}{l}\text { Feelings, } \\
\text { emotions, } \\
\text { attitudes }\end{array}$} & Don't like maths & Positive emotions towards maths \\
\hline & Have to do it & A utility towards maths \\
\hline & Negative emotions towards maths & Can understand maths, maths is easy \\
\hline & I am not good at maths & Will be useful when I am older \\
\hline & May be useful when I am older & \\
\hline \multirow[t]{8}{*}{ Practices } & $\begin{array}{l}\text { Maths is for survival e.g. job at } \\
\text { McDonalds }\end{array}$ & $\begin{array}{l}\text { Maths if for when I am a doctor or a } \\
\text { teacher }\end{array}$ \\
\hline & Negative expressions regarding & Positive towards the teachers \\
\hline & teachers & Competitive learning environment \\
\hline & $\begin{array}{l}\text { Difficulty with the mechanics of } \\
\text { mathematics }\end{array}$ & $\begin{array}{l}\text { Shut down groups where there is } \\
\text { streaming }\end{array}$ \\
\hline & Teacher quality was generally poor & Teacher quality is very high \\
\hline & $\begin{array}{l}\text { Like group work - social, material, } \\
\text { pedagogy (constructivist) }\end{array}$ & $\begin{array}{l}\text { Able to articulate pedagogical } \\
\text { approaches }\end{array}$ \\
\hline & $\begin{array}{l}\text { Content is a challenge (often with } \\
\text { operations) }\end{array}$ & $\begin{array}{l}\text { Maths is logical, linear, one answer } \\
\text { (conservative) }\end{array}$ \\
\hline & $\begin{array}{l}\text { Maths is for working out change at } \\
\text { the shops }\end{array}$ & $\begin{array}{l}\text { Clearly articulate about the purpose } \\
\text { of maths }\end{array}$ \\
\hline
\end{tabular}

Using the data we collected, we now seek to understand these phenomenon using the two paradigms. A simple rendering of these results could suggest that the practices at School B are quite poor, and that the students have internalised these practices with a consequence being the development of poor self-concepts and attitudes towards mathematics. In contrast, the reverse appears to be the case for students at School C. In coming to better understand the phenomenon reported by the students, we draw on our two paradigms and use the key constructs and example terminology we presented earlier in Table Two. This creates a much richer rendering of the data than placing blame on schools and teachers per se.

\section{A Psychological Standpoint}

In understanding the comments offered by the students we initially draw on psychological constructs. The analysis of our data draws on some of the constructs in Table Two. We have published this elsewhere (Authors 2015) indicating that perceived difficulty and lack of confidence are important reasons for students not continuing with mathematics, and that perceived dislike, boredom and lack of relevance are also factors that feature prominently in the student data analysed in this article. There is a close relationship between reasons for non-participation and predicted grade, and there is a weaker relationship to gender (Authors 2015). An analysis of the effects of the school teaching of mathematics in our 
previous research demonstrated that enjoyment was a main factor differentiating schools with high and low participation indices.

In addition, what we initially observed were clear examples of affect and self-concept in student comments from both schools. In School B the students appear to have internalised a belief system that they are not strong in mathematics, that the mathematics that they encounter is quite difficult, and that this resonates with their own beliefs about themselves as learners. However, School C students appear to have internalized an approach to mathematics whereby it is accepted as a normal component of their school routine with no significant negativity or challenge to their self-notion as learners (Authors 2015).

What is evident in these comments is that both groups of students have a reified sense of who they are in terms of learners of mathematics. The students from School B were more likely to have a poor sense of themselves as learners, while the students at School C had a much more robust sense of themselves. Dweck's (2012) seminal work on mindsets shows how fixed and flexible mindsets are important factors in how students approach learning in general, and mathematics in particular. For Dweck, when students and teachers see or describe behaviours as being 'clever' this suggests that there is a fixed or reified mindset and that success is due to some innate ability. In contrast, the flexible mindset is a more practical approach so that when students hit a stumbling block they have strategies to solve questions, rather than hitting a brick wall because they cannot solve the task. What is clear from the students' responses (samples provided below) is that the students from School B are more likely to have a fixed mindset with regard to their mathematical "ability" "I' $m$ just more of an English kind of person", whereas the students at School C talked more about their dispositions towards mathematics and their strategies to solve problems "What I like about maths is that there are different ways you can sort things out - like chunking". From Dweck's standpoint, the mindsets that the students have developed (and internalised) are highly influential in determining their future success. This value of Dweck's psychological theory helps to explain the notion of fixed ability and how students see themselves as learners.

There was also considerable evidence from the data collected from the two schools that there were two very different sets of attitudes and emotions associated with mathematics. That is not to say that they were unanimous in their responses, but rather that there were greater numbers of responses in clusters of emotions and dispositions from one school than the other. The students at School B were more likely to comment on feelings of sadness and frustration with mathematics 'My teacher doesn' t really help me that much, she helps other kids, but she doesn't really help me. I do feel sad when I do maths, I feel so sad because I' $m$ going through all that trouble and I don' t need to go through it." and "Then I start to cry because she makes me really angry. Like, how do I explain it? I HATE MATHS!!" whereas the students at School C were more likely to report positive experiences of mathematics "So I really like maths. I feel happy when I do maths because it makes you feel good and makes you feel like you're in a different world. And if I got in trouble I would start doing maths because it makes you feel a lot happier". The internalisation of these feelings towards mathematics have often been framed in the wider literature of affect, beliefs and attitudes, which are portrayed as attributes of the learners, and the impact of these attributes on their learning of mathematics. Again, the theories within the psychological paradigm help to explain the comments around students' feelings, attitudes, beliefs and emotions towards mathematics. This is a very comprehensive area in mathematics education and provides tools and constructs through which student data can 
be interpreted.

The comprehensive account of communities of practice offered by Wenger (1999) unites many of the psychological constructs into a comprehensive account of understanding how particular communities - e.g. classrooms - offer ways (practices) through which students come to be learners of mathematics. Within this framing (a social psychological framing), Wenger raises the processes - such as ability grouping, group work, competitive learning as identified by the participants - through which students come to see themselves as legitimate learners or ones who remain at the periphery of mathematics. The data provided by the students suggest to us that the students at School B see mathematics as something that is highly functional (getting a job at McDonalds or being able to work out the correct change) and largely contained to computations - "It is important because later in life when you get a job, you'll have to figure out things or how much they want or how much it costs". In contrast, the students at School C saw mathematics as an academic endeavour that enabled (and empowered) them to be highly successful in the world beyond school (doctors, engineers) - "because everyday life you'll need it as a doctor how much medicine to give someone, as a teacher everything pretty much". Thus, the utilitarianism that was primarily evident in the discourses of the School B students was in contrast to the empowerment evidenced by the students at School C. From a communities of practice perspective, the students at School B were being inducted into a limiting worldview of mathematics, whereas the community for the students at School $\mathrm{C}$ was far more empowering. Collectively these experiences indicate different mathematical pathways for the two cohorts in their secondary schooling and beyond.

The psychological paradigm offers many theories and constructs through which the data can be interpreted. Their value is in the explanatory power offered through this paradigm about the individual within the context of mathematics education. These theories offer a range of ways of interpreting various aspects of our data that have been useful. They are somewhat limited though when we consider the differences between the two schools. To this end, the theories and constructs offered through a sociological rendering of our data offered other ways of interpreting the data.

\section{A Sociological Standpoint}

In undertaking our sociological analysis, we draw on critical sociology that seeks to understand the ways in which practices and structures shape behaviours. In so doing, we come to understand the same set of observations discussed previously as being potential outcomes of the students' engagement (or failure to engage) with the practices of school mathematics. This sociological rendering of the data provides a different way of viewing the same students' comments. From a sociological standpoint, the structures (or practices) that support or hinder students' experiences in mathematics education become the focus of analysis. From a sociological framework perspective, we argue for the presence of sets of hegemonic practices that align with particular social, cultural, linguistic and gendered approaches to mathematics. Where a student's background, language, or gender align with the practices of mathematics in a specific context, then there is a greater chance of success. That is not to say that students whose background is different from those practices of school mathematics will be excluded, but rather, those students will have to realign their home backgrounds with the practices of school mathematics if they are to be successful.

From a critical-sociological standpoint, the data demonstrated that the students from 
School B were being marginalised in their study of mathematics, while the students at School $\mathrm{C}$ were more likely to have their social and cultural backgrounds recognised and seen as an integral part of the mathematics education practices offered at the school. Using the constructs offered through Bourdieu's work, we contend that the habitus that the students bring to each school is differentially acknowledged and rewarded. For students to be successful at School B, they need to reconstitute this habitus such that it aligns with the middle-class habitus largely represented in primary school mathematics classrooms. This is not the case for the School C students who come to school with a middle-class habitus such that they are able to engage readily and easily with mathematics. Students at School C also saw mathematics as being logical, linear and often with only one correct answer. While this may reflect a conservative view of mathematics, we would also contend that this is a dominant view of the ontology of mathematics education. In contrast, the view of the students at School B was that mathematics was an endeavour that was of little value in their "non-school" worlds and with little utility for their future. We see, for example, that the School B students have a restricted and utilitarian view of school mathematics (survival and basic employment) whereas the School C students have a more expansive view of school mathematics that will likely support them into highly paid (middle-class) professions.

Many of the responses we noted earlier can be seen as part of the doxa that Bourdieu describes as a 'feel for the game'. Being able to identify, interpret and engage with the practices in school mathematics is not dissimilar to playing a game such as football. Often the rules - such as socio and cultural norms - of a classroom are not made explicit to learners so they need to be able to read these norms if they are to engage successfully in the interactions within the classroom. This is what Bourdieu refers to as "doxa" - an ease with the implicit and often unspoken rules of the classroom. In the contexts of the two schools, we can see that the students at School B may not have a feel for the game of mathematics - they see it via a utilitarian lens and that it is "something they have to do" rather than as an academic pursuit that offers considerable rewards in its own right. The students at School $\mathrm{C}$ were more likely to see mathematics in a much more positive framing and as an important (and valuable) area of study for their future work. This doxa, or feel for the game of school mathematics, is important in terms of students seeing the intrinsic value of mathematics as a field of study. At another level, students' doxa at the level of the classroom i.e. the enactment of practices within the classroom, were also very different.

The students at School $\mathrm{C}$ were very articulate about the various pedagogical practices employed by teachers and could evaluate their value in terms of teaching mathematics " $I$ know the chunking strategy and that's really helping me with all of my dividing" and "today in maths I learnt some more about tree diagrams where we had to get different flavours of ice creams and toppings and cones and we had to show all the different combinations". In contrast, the students at School B had a very restricted understanding of the practices used in school mathematics. Their doxa was framed quite differently from their School C counterparts. The School B students barely commented on strategies or learning practices and were much more likely to talk about mathematics as having no connection with their world, or to comment specifically on content they are experiencing difficulty with - "I could use more help with the square root of and like additions and times tables".

These differences in the students' views of mathematics may well be a reflection of their mathematical habitus, constructed through their home experiences, and then either 
reinforced or challenged through school experiences. The students from School $\mathrm{C}$ have a mathematical habitus that appears to align with the empowering values of mathematics, while the students from School B have a very functionalist, limited view of mathematics. The internalization of the practices of the two schools becomes part of the students' habitus and, as observed in the previous section, the embodiment of these practices has produced very different dispositions within the learners. A more comprehensive account of the experiences of the students becomes possible through the use of a sociological analysis. Using this framework, we are better able to understand the structuring processes that have end products of (dis)engagement or (un)happiness.

One of the more salient structuring practices observed in the student data were their perceptions of teacher quality. Within the psychological paradigm, the teacher quality discussion would emphasise the characteristics of teachers such as their content knowledge or pedagogical knowledge. In contrast, within the sociological paradigm, the quality of the teacher is seen as a practice that either enables or excludes students. The students at both schools raised concerns about teacher quality. We do not seek to engage in debate about our views as to the quality of the teachers and their teaching of mathematics, rather we draw on the students' responses. What was very clear from the two schools was that the students at School B often reported negative aspects in the teaching they received. "The teacher could help me more with maths by showing more respect to the people" AND "The teacher could help me more instead of yelling at me. My teacher doesn't really help me that much" and "I don' t like when you were listening but you don' $t$ understand the thing that the teacher is asking you to do and you feel a bit scared to ask questions because you might get in trouble or you might be embarrassed".

Conversely, the students at School $\mathrm{C}$ were far more positive in their assessment of their teachers and indicated general satisfaction which could primarily be improved upon by the teachers providing a little more one to one help - "The teacher could help me with more by sitting with me". However, whilst generally positive, the students in School C commented negatively on the teaching practice of streaming, indicating that they felt less connected to their teacher when streamed. "I'd tell them to shut down the maths group system because I like working with Mrs. Dale (pseudonym) better, my form teacher, because she knows me better and I'd really like them to shut down the whole maths groups thing".

What is possible through a sociological paradigm, and in particular a Bourdieuian lens, is to identify these assessments as being part of the objective structuring practices of the schools. At School B the structures (in this case the teachers) were perceived by the students as being poor, and thus offering the students a poor experience in mathematics. In this way, the students were being marginalised in the study of school mathematics through the perception, real or otherwise, that they were not being adequately supported in their study of mathematics. It is possible that this may be the case as it was a commonly reported phenomenon that the School B students reported that they struggled with basic number knowledge in mathematics. This is a low level skill in the curriculum and yet it occupied a significant amount of the responses offered by the School B students "I could use more help with fractions. Because I find them difficult and also multiplication, I'm getting better at them but I haven't learned my 11's and 12's yet'. In contrast, the students at School C reported that they were exposed to very good teachers of mathematics and that they were given strong opportunities to learn mathematics. Unlike the School B students, the School C students reported high levels of mathematics learning "I especially like chance and tree diagrams and...how many outcomes" and "I love learning about new 
angles such as acute, reflex, straight and many others". Collectively, the structuring practices of the schools, vis a vis the teacher quality, provided very different experiences for the students, and had potentially significantly different learning outcomes for the students. These experiences shaped the habitus of the learners in very different ways, either marginalising or empowering them.

\section{Implications for Understanding Who Succeeds in Mathematics}

Our aim in this article was to bring about a richer, more complex rendering of student voices. We do not make assertions about the unique sites, nor intend to make any definitive claims based on broad social outcomes, but rather our aim was to illustrate how the tools of analysis have provided ways to understand the phenomenon to which the students speak. Using both paradigms we are better able to understand and frame the comments offered by the students. We argue that the analytical framework we created could be applied more robustly given a larger data set from a more comprehensive range of schools. Traditionally, mathematics education has given a strong voice and validity to those analyses that we have named within this article as being psychological. This has provided valuable insights into students' renderings of their experiences in, and of, school mathematics. However, we have sought to enrich these analyses by undertaking a concurrent sociological analysis of the same data. Collectively these analyses provide a richer rendering of the data and help us to explain the different experiences of the students, and how these impact on their understandings and embodiment of the practices of school mathematics. We will continue to collect data to enable an increased level of robustness in the use of the analytical frameworks presented here.

The purpose of this article was to explore the value in drawing on two paradigms to better understand data. The data used in this article has been for illustrative purposes. Ideally a much bigger sample, across more schools, would enable a richer understanding and also help to address the potential for our data to be skewed given our small sample size. What we have sought to do is to illustrate the potential of two paradigms to understand a phenomenon. We could have explored the use of other paradigms such a feminist paradigm to explore gendered differences more specifically or a linguistic paradigm to explore the features of language use particularly along the lines of social stratification, or a mathematical paradigm where we explored the types of mathematics that students were working on. We acknowledge that these are all paradigms through which to view student experiences in mathematics.

While this article is limited by the participant sample size, it was initially designed as a case study approach. What has emerged from the data is that the initial rendering of the data with a psychological framework provided us with some insights into students opting out of mathematics. The opting out could be seen as something that the students were either consciously or unconsciously selecting. However, upon further analysis, we could also see that there were clearly patterns in the students' responses that related to the social contexts of their mathematical experiences. To this end, we found that richer interpretations of the data were possible when we also considered a sociological rendering of the responses. Collectively we were better able to theorise the opting out of the students as being not simply a psychological process, but one shaped by the practices of their respective schools. By undertaking an analysis using the two frameworks, it becomes possible to better understand how the practices shape the potential for learning and 
learners, and at the same time, consider the internalization of these practices that shape the identities (or habitus) of the learners. Through this dual rendering of the data, we are better able to appreciate the nuances within classrooms and their impact on learners. It becomes possible to critically appraise the social milieu of mathematics classrooms and how to change them so as to enable greater access for learners, particularly those who have been traditionally excluded from mathematics.

Acknowledgement: This project was initially funded through a Griffith AEL research grant scheme. We also acknowledge the contribution of Associate Professor Peter Gates (Nottingham University) in earlier components of this project. Aspects of this article have been presented at earlier MERGA and PME conferences. However, this article is a substantive development of this earlier work.

\section{References}

Author (2010).

Authors (2015).

Authors (2015).

Author (2014).

Angus, D., Rintal, S. \& Wiles, J. (2013). Making sense of big text: A visual-fist approach for analysing text data using Leximancer and Discursis. International Journal of Social Research Methodology, 16(3), 261-267.

Australian Curriculum Assessment and Reporting Authority (2015). My school. Retrieved from http://www.myschool.edu.au/

Bourdieu, P. (1977). Outline of a theory of practice. Cambridge: Cambridge University Press.

Bourdieu, P., Passerson, J. \& De Saint Martin, M. (1994). Academic Discourse: Linguistic Misunderstanding and Professorial Power. Stanford University Press. Stanford.

Boylan, M. (2010). Ecologies of participation in school classrooms. Teaching and Teacher Education, 26(1), 61-70.

Brown, M., Brown, P. \& Bibby, T. (2012) "I would rather die": reasons given by 16-year-olds for not continuing their study of mathematics, Research in Mathematics Education, 10(1), 3-18.

Buchwald, D., Schantz-Laursen, B., \& Delmar, C. (2009). Video Diary Data Collection in Research with Children: An Alternative Method. International Journal of Qualitative Methods, $8(1), 12-20$.

Di Martino, P., \& Zan, R. (2009). 'Me and maths': towards a definition of attitude grounded on students' narratives. Journal of Mathematics Teacher Education, 13(1), 27-48.

Dweck, C. (2012). Mindset: How you can fulfil your potential. Robinson Publishing, London, UK.

Hannulu, M. (2012) Exploring new dimensions of mathematics-related affect: embodied and social theories. Research in Mathematics Education 14(2), 137-161. 
Korhnonen, J. Tapola, A., Linnanmaki, K. \& Aunio, P. (2016) Gendered pathways to educational aspirations: The role of academic self-concept, school burnout, achievement and interest in mathematics and reading. Learning and Instruction, 46 (1), 21-33.

Lamb. S. (2012). School dropout and completion in Australia. In S. Lamb, E. Markussen, R., Teese. J. Polesle, \& N. Sandberg. (Eds.) School dropout and completion: International Comparative studies in Theory and Practice, (pp. 321-339). Dordrecht: Springer.

Lewis, G. (2013) Emotion and disaffection in school mathematics. Research in Mathematics Education, 15(1), 70-86.

Lewis, G. (2014). The incidence of disaffection with school mathematics. In P.Liljedahl, S. Oesterle, C. Nicol \& D. Allan (Eds.) Proceedings of the Joint Meeting 4-121 of PME 38 and PME-NA 36, Vol. 4, pp. 121-128. Vancouver, Canada: PME.

Lundström, M. (2013). Using video diaries in studies concerning scientific literacy. Electronic Journal of Science Education, 17(3).

Ma, X. \& Kishor, N. (1997). Assessing the Relationship between Attitude toward Mathematics and Achievement in Mathematics: A Meta-Analysis. Journal for Research in Mathematics Education, 28(1), 26-47.

Noyes, A. (2004a). Learning landscapes. British Educational Research Journal, 30(1), 27 - 41.

Noyes, A. (2004b). Video diary: a method for exploring learning dispositions. Cambridge Journal of Education, 34(2), 193-209. doi: http://dx.doi.org/10.1080/03057640410001700561

Radford, L. (2015). Of Love, Frustration, and Mathematics: A Cultural-Historical Approach to Emotions in Mathematics Teaching and Learning. In B. Pepin \& B. Roesken-Winter (Eds.), From beliefs to dynamic affect systems in mathematics education (pp. 25-49): Springer International Publishing.

Tranter, D. (2012) Unequal schooling: How the school curriculum keeps students from low socioeconomic backgrounds out of university. International Journal of Inclusive Education 16(9), 91-916.

Walshaw, M. (2011). Positive possibilities of rethinking (urban) mathematics education within a postmodern frame. Journal of Urban Mathematics Education. 4(2), 7-14

Wenger, E. (1999). Communities of practice: Learning, meaning and identity. Cambridge: Cambridge University Press.

Zevenbergen, R. \& Flavel, S. (2007). Undertaking an archaeological dig in search of pedagogic relay. Montana Mathematics Enthusiast, Special Monograph 1, (International Perspectives on Social Justice in Mathematics Education), 63-74 